\title{
ANALISIS PENGGUNAAN IP PUBLIK PADA BROADBAND NETWORK GATEWAY DALAM LAYANAN INTERNET PT INDONESIA COMNET PLUS
}

\author{
Eri Dwi Fariliana \\ Sekolah Vokasi, Program Studi Teknologi Rekayasa Internet \\ Universitas Gadjah Mada \\ Email: eri.dwi.f@mail.ugm.ac.id \\ Hidayat Nur Isnianto \\ Sekolah Vokasi, Program Studi Teknologi Rekayasa Internet \\ Universitas Gadjah Mada \\ Email: hnisnianto@ugm.ac.id
}

\begin{abstract}
ABSTRAK
Internet merupakan kumpulan jaringan komputer yang ada di seluruh dunia dan dapat saling berkomunikasi. Penyediaan internet tidak lepas dari penggunaan IP publik. IP publik memiliki keterbatasan yaitu jumlah IP terbatas serta harga yang mahal. Menanggapi hal tersebut ICON+ mulai menerapkan penggunaan Broadband Network Gateway (BNG). Sistem pengalokasian IP publik dengan BNG mengalokasikan IP network dan broadcast pada subnet 255.255.255.0 (/24) kemudian membagikan IP untuk pelanggan (CPE) dengan subnetting 255.255.255.255 (/32), sedangkan pada Virtual Routing Forwarding (VRF) mengalokasikan IP network dan broadcast dilakukan pada setiap service serta subnetting disesuaikan dengan kebutuhan service. Hasil penelitian menunjukan bahwa kebutuhan IP publik yang sedikit sangat cocok dikonfigurasi dengan BNG dan konfigurasi VRF lebih cocok digunakan untuk kebutuhan service internet dengan kebutuhan banyak IP publik. Penelitian ini juga menunjukan bahwa penggunaan BNG tidak terlalu mempengaruhi performa service internet karena performa jaringan sangat baik pada parameter throughput dengan nilai $96.7 \%$ dan delay dengan nilai $22.058 \mathrm{~ms}$ serta baik untuk parameter packet loss dengan nilai $0.1 \%$ dan jitter dengan nilai $4 \mathrm{~ms}$.
\end{abstract}

Kata kunci: IP publik, broadband network gateway, virtual routing forwarding, quality of service.

\begin{abstract}
The Internet form an association of computer that exist throughout the world and can communicate with each other. Internet provision can not be separated from the use of public IP. Public IP has limitations of limited IP numbers and expensive. Responding to this ICON+ began implementing Broadband Network Gateway (BNG). The public IP allocation system with BNG allocates IP networks and broadcasts on subnet 255.255.255.0 (/24) then distributes IP for CPE with subnetting 255.255.255.255 (/32), while in Virtual Routing Forwarding (VRF) allocate IP network and broadcast done on each service and subnetting corresponding to service requirement. The results show that the needs of some public IP is suitable to be configured with BNG and VRF configuration is more suitable for internet service requirement with many public IP. This study also shows that the use of BNG does not significantly affect the performance of internet service because of excellent network performance on throughput is $96.7 \%$ and delay $22.058 \mathrm{~ms}$ and good for packet loss $0,1 \%$ and jitter $4 \mathrm{~ms}$.
\end{abstract}

Keywords: public IP, broadband network gateway, virtual routing forwarding, quality of service.

\section{PENDAHULUAN}

Internet merupakan kumpulan jaringan komputer yang ada diseluruh dunia dan dapat saling berkomunikasi. Berbicara mengenai penyediaan internet tidak lepas dari peran Internet Service Provider (ISP) sebagai penyedia layanan internet. PT. Indonesia Comnets Plus (ICON+) merupakan salah satu perusahaan ISP yang menyediakan layanan internet [1]. Penyediaan internet tidak lepas dari penggunaan IP publik. Sebelumnya layanan internet ICON+ menggunakan teknologi Virtual Forwarding Routing (VRF). VRF mampu digunakan dalam jaringan skala besar karena mendukung penggunaan multi instance routing protocol sehingga overlapping IP address tidak menjadi suatu masalah [2] [3] [4].

Dalam penggunaan teknologi VRF pengalokasian IP publik pada teknologi VRF dilakukan setiap layanan, pembagian IP terkendala dengan subnetting IP yang tidak bisa menyediakan IP tepat dengan 
kebutuhan. Sedangkan IP publik berifat unik memiliki keterbatasan jumlah IP serta harga yang mahal [5]. BNG dinilai mampu melakukan penghematan IP publik, selain itu penggunaannya juga mampu mempermudah monitoring IP publik, menambah keamanan jaringan, dan mempermudah perhitungan penggunaan bandwidth [6].

BNG memiliki konsep session dalam membuat suatu service internet. Konsep penggunaan session pernah dilakukan untuk melakukan penghematan IP pada perangkat mobile dengan membuat mobile node, dalam sistem tersebut terdapat calling-in dan calling-out session untuk penggunaan kembali IP pada host lain setelah session berakhir [7].

ICON+ mulai menerapkan penggunaan Broadband Network Gateway (BNG) dalam pengalokasian IP publik. Pengimplementasian BNG ternyata mengalami beberapa kendala yaitu sistem pengalokasian bandwidth hanya dapat dilakukan per satu IP sehingga kesulitan melayani kebutuhan satu bandwidth untuk beberapa IP dan BNG harus mengetahui session pada suatu subscriber aktif sehingga dikhawatirkan akan mempengaruhi kualitas performa jaringan seperti nilai throughput, delay, jitter, dan packet loss. Padahal dalam mengembangkan metode layanan yang digunakan oleh perusahaan analisis performansi jaringan sangat penting untuk diperhatikan [8]

Oleh karena itu diperlukan penelitian lebih lanjut untuk memaksimalkan penggunaan BNG dalam memenuhi suatu kebutuhan layanan internet baik dari sisi pengalokasian IP publik dan performa layanan dengan parameter throughput, delay, jitter, dan packet loss.

\section{METODOLOGI PENELITIAN}

\subsection{Alat dan Bahan}

Dalam melakukan penelitian ini dibutuhkan alat yang berupa perangkat keras dan bahan berupa perangkat lunak diantaranya :

a) Perangkat keras

Spefisikasi perangkat keras untuk pengujian termuat pada Tabel 1

Tabel 1. Spesifikasi perangkat keras

\begin{tabular}{|c|c|c|}
\hline Perangkat & Nama Perangkat & Jenis \\
\hline 1 Router $\mathrm{BNG}$ & JKT-GANDUL-XXXXX- & Cisco ASR9000 \\
\hline 1 Router UPE & JKT-GANDUL-XXXXX- & Cisco ASR920 \\
\hline 1 Switch $\mathrm{CPE}$ & $\mathrm{HP}$ & HP A3100 \\
\hline 1 Komputer & Eri-PC & Lenovo ideapad \\
\hline $1 \quad$ Kabel & - & - \\
\hline 1 Kabel Fiber & - & - \\
\hline 1 Kabel UTP & - & straight \\
\hline 2 Konektor & - & xcore \\
\hline
\end{tabular}

b) Perangkat lunak
1) Putty
2) WireShark
3) Microsoft Edge
4) Microsoft Excel

\subsection{Prosedur Penelitian}

\subsubsection{Implementasi Sistem Pengujian}

Perancangan sistem untuk eksperimen penelitian ini menggunakan topologi seperti yang tersaji pada Gambar 2 Pada gambar tersebut router BNG dengan nama JKT-GANDUL-XXXXX-BNG-01. Terdapat jaringan MPLS yang menghubungkan Provider Edge (PE) terdekat dari Customer Edge (CE) ke router BNG. CE terhubung ke BNG melalui PE terdeket yaitu JKT-GANDUL-XXXXX-UPE-01, PE terdekat berfungsi menghubungkan CE ke BNG. Jaringan ke arah CE ditambahkan perangkat switch HP. Pengambilan data performa dilakukan pada sisi CPE atau ERI-PC. 


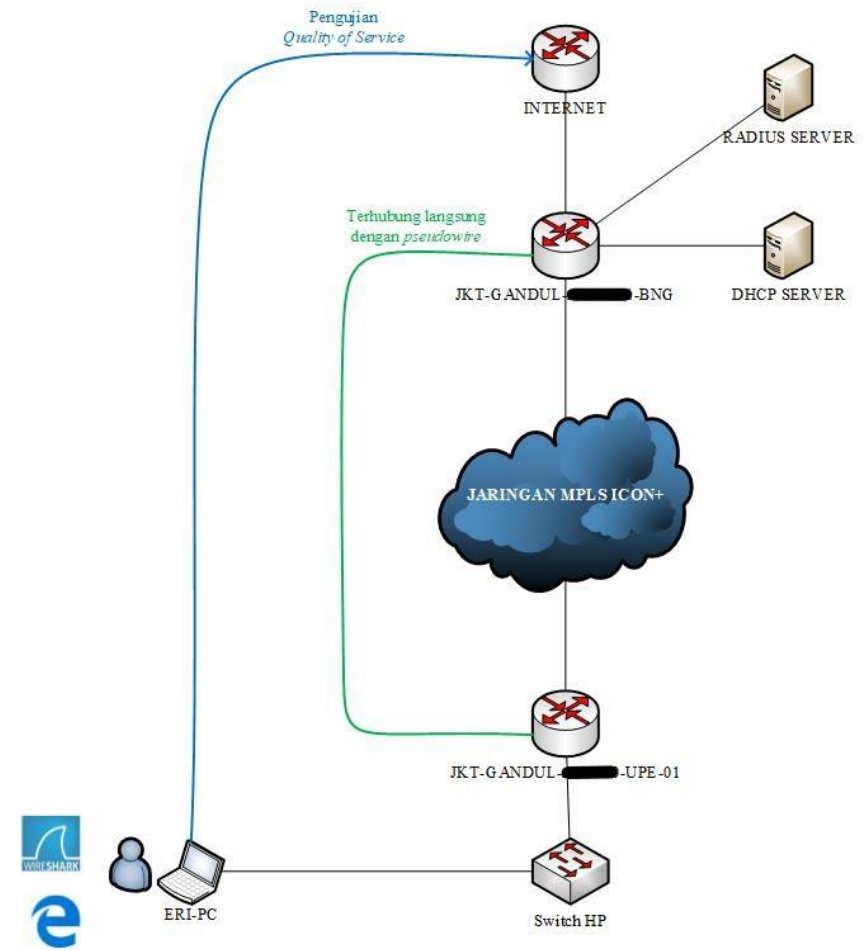

Gambar 2. Topologi penelitian

\subsection{Metode Pengujian}

\subsubsection{Konfigurasi Service}

a) Konfigurasi Service BNG

Konfigurasi BNG yang dilakukan dalam penelitian ini dilakukan sesuai dengan sistem pengimplementasian pada PT ICON+ karena peneliti melakukan pengambilan data pada perusahaan tersebut. Pada arsitektur penelitian ini UPE berperan sebagai DSLAM, UPE terhubung ke router BNG dengan menggunakan pseudowire. Hal tersebut membuat seolah-olah terdapat kabel yang menghubungkan UPE langsung ke router BNG, pseudowire berkomunikasi menggunakan data link layer atau lapisan kedua pada OSI layer. Kemudian jenis session yang digunakan pada penelitian ini yaitu IPoE (IP over Ethernet) yaitu proses delivery IP publik dilakukan melalui jaringan ethernet atau lokal ICON+ yaitu melalui jaringan MPLS seperti yang tersaji pada Gambar 2.

b) Konfigurasi Service VRF

Berikutnya konfigurasi VRF dilakukan dengan mengambil konfigurasi service internet yang berada pada terminasi yang sama dengan tempat pengujian namun tidak dapat dilakukan pada perangkat pengujian yang sama dikarenakan pengalokasian IP publik untuk pengujian VRF mempengaruhi proses bisnis yang berlangsung di perusahaan karena jumlah IP terbatas.

\subsubsection{Penghitungan Penggunaan IP}

Penghitungan penggunaan IP publik dilakukan dengan membandingkan penggunaan metode pengalokasian IP dengan menggunakan BNG dan VRF pada 800 service, 1000 service, dan 1200 service dengan kebutuhan IP publik valid yang dapat digunakan pada setiap service yaitu 1 IP, 4 IP, dan 8 IP sehingga diperoleh enam data dalam bentuk grafik yang tercantum pada Tabel 2.

Tabel 2 Skenario penghitungan IP publik

\begin{tabular}{|c|c|c|c|}
\hline \multicolumn{3}{|c|}{ No. Metode Pengalokasian IP Kebutuhan IP } & Jumlah Service \\
\hline \multirow{4}{*}{1} & & & 800 service \\
\hline & & 1 & 1000 service \\
\hline & $\mathrm{BNG}$ & & 1200 service \\
\hline & & & 800 service \\
\hline \multirow[t]{2}{*}{2} & & 4 & 1000 service \\
\hline & & & 1200 service \\
\hline
\end{tabular}




\begin{tabular}{lcl}
\hline No. Metode Pengalokasian IP & Kebutuhan IP & Jumlah Service \\
\hline \multirow{3}{*}{3} & & 800 service \\
& & 1000 service \\
& & 1200 service \\
4 & & 800 service \\
& & 1000 service \\
& & 1200 service \\
5 & & 800 service \\
& & 1000 service \\
& & 1200 service \\
6 & 4 & 800 service \\
& & 1000 service \\
& & 1200 service \\
\hline
\end{tabular}

Parameter penggunaan IP yang digunakan untuk penghitungan perbandingan penggunaan BNG dan VRF adalah jumlah IP yang digunakan untuk network, broadcast, alokasi per pembelian IP publik yaitu per 256 IP atau pada subnetwork 255.255.255.0 atau dengan prefix /24 dan jumlah IP layanan (jumlah IP host untuk layanan) pada setiap service sesuai dengan skenario yang telah disebutkan sebelumnya.

\subsubsection{Pengujian Performa}

Dalam penelitian ini juga didapat data performa penggunaan service internet dengan menggunakan BNG. Data yang dihasilkan berupa hasil dari speed test dan hasil perhitungan data perekenaman pengujian akses internet dengan menggunakan WireShark. Data speed test digunakan untuk mengetahui nilai dari throughput upload dan throughput download, sedangkan data dari WireShark digunakan untuk melakukan pehitungan nilai delay, jitter, packet loss, dan throughput. Data speed test didapat dengan menggunakan speed test PT ICON+ yaitu "http://speedtest.iconpln.net.id/" yang diakses dengan Microsoft Edge. Data dari WireShark akan diubah dalam bentuk Microsoft Excel untuk mempermudah proses penghitungan nilai delay, jitter, packet loss, dan throughput.

\section{HASIL DAN PEMBAHASAN}

\subsection{Pengalokasian IP}

\subsubsection{Konfigurasi BNG}

Dalam membuat suatu service internet dengan menggunakan BNG terdapat tiga bagian perangkat yang perlu dikonfigurasi yaitu web server BNG, UPE, dan CPE. Web server BNG menghubungkan RADIUS server dan DHCP server melalui lapisan ke tujuh atau aplication layer OSI layer.

a) Konfigurasi RADIUS pada web server $\mathrm{BNG}$

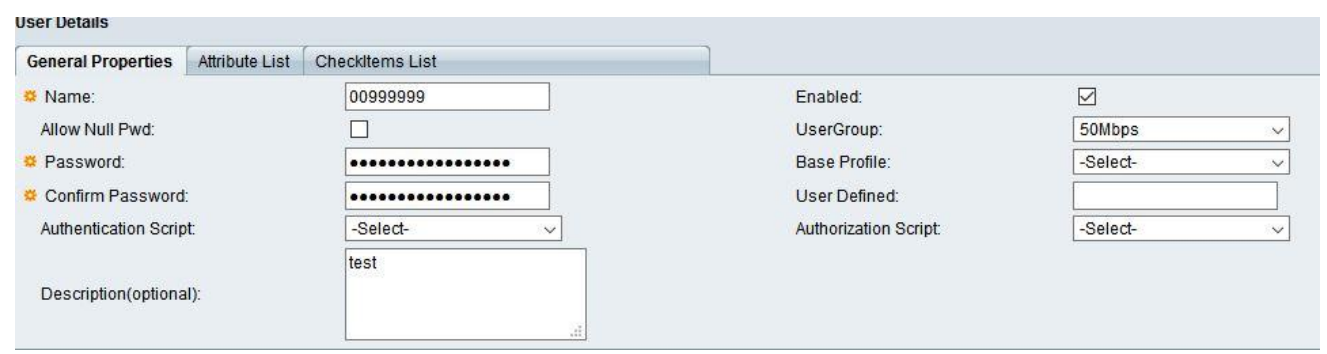

Gambar 3. Konfigurasi RADIUS pada Web Server BNG

Pada Gambar 3 merupakan tampilan dari aplication layer router BNG dalam melakuakn konfigurasi RADIUS server. Konfigurasi hanya perlu dilakukan pada menu "General Properties" dimana data yang diperlukan untuk melakukan konfigurasi tersebut adalah "Name", "Password", dan "Confirm Password". Selain data pokok tersebut pengujian menambahkan penggunaan data "Enable", dan "UserGroup" sesuai dengan implementasi penyediaan service internet yang dilakukan oleh PT ICON+. 
Pada konfigurasi ini membuktikan bahwa sistem dasar BNG yang ada di PT ICON+ adalah satu bandwidth per satu IP. Pengalokasian secara kelompok seperti beberapa IP dengan alokasi satu bandwidth tidak dapat dilakukan secara fleksibel pada sistem dasar pada aplication layer. Apabila pengalokasian bandwidth untuk beberapa IP publik tetap ingin dilakukan pada konfigurasi di application layer dan terpusat di BNG maka pembagian dialakukan secara manual, misalnya dalam konfigurasi ini kebutuhan bandwidth adalah $50 \mathrm{Mbps}$ dan terdapat 3 IP maka pengalokasian bandwidth dapat dilakukan dengan IP pertama $20 \mathrm{Mbps}$, IP kedua $20 \mathrm{Mbps}$, dan IP ketiga $10 \mathrm{Mbps}$. Dari masalah tersebut diperlukan konfigurasi lain untuk memungkinkan pengalokasian bandwidth untuk beberapa IP publik yang dialokasikan dengan BNG. Konfigurai tersebut dapat dilakukan pada UPE.

b) Konfigurasi $\mathrm{DHCP}$ pada web server $\mathrm{BNG}$

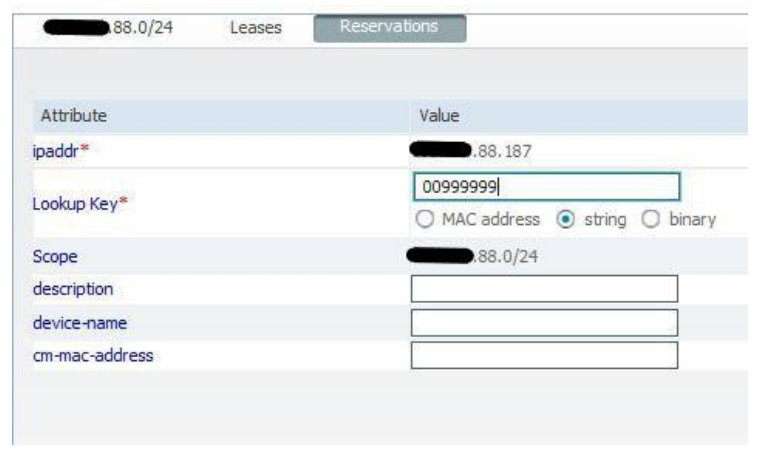

\section{Gambar 4. Konfigurasi DHCP pada web server BNG}

Tahap berikutnya dalam pembuatan suatu session service internet menggunakan BNG adalah dengan melakukan reservasi pada DHCP server seperti tampilan yang tersaji pada Gambar 4 yang diperlukan pada konfigurasi ini adalah data "Name" yang ada pada konfigurasi RADIUS server atau "circuit-id". Data tersebut menggunakan "String" sebagai proses autentikasi dan autorasi.

Proses reservasi IP publik dalam sistem ini terdapat dua jenis yaitu secara DHCP dan statik. Reservasi dengan menggunakan sistem DHCP menggunakan data "circuit-id" sedangkan apabila menggunakan sistem statik maka diperlukan MAC address dari perangkat CPE.

c) Konfigurasi UPE

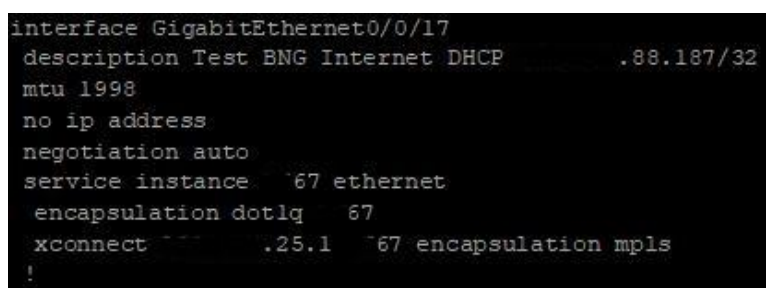

Gambar 5. Konfigurasi UPE

Konfigurasi pada UPE cukup sederhana yaitu dengan membuat VLAN yang sesuai dengan pengelompokan IP pada router BNG yang telah di reservasi sebelumnya. Kemudian melakukan konfigurasi pseudowire untuk menghubungkan CPE ke router BNG. Apabila penyediaan service BNG berhadapan dengan kebutuhan service lebih dari satu IP publik maka konfigurasi BNG pada UPE dapat membantu pembatasan bandwidth dari service internet. Sistem pembuatan username (circuit-id) untuk pada RADIUS dan reservasi IP di DHCP server disesuaikan pada jumlah perangkat. Hal tersebut membuat pengalokasian satu bandwidth dapat dilakukan pada beberapa IP publik dengan BNG, namun konfigurasi ini mengharuskan mengkosongkan alokasi bandwidth pada konfigurasi RADIUS server sehingga alokasi bandwidth yang sebenarnya digunakan pada service tersebut tidak termonitoring secara terpusat di BNG. Pembatasan bandwidth dilakukan pada port yang terhubung ke CPE. Dalam kasus ini bila CPE penerima IP publik terdapat lebih dari satu perangkat, maka pembatasan dilakukan pada port UPE yang terhubung ke CPE. Pembatasan dengan menambahkan service police IN dan OUT pada port interface yang mengarah ke CPE yaitu "GigabitEthernet0/0/17". Contoh konfigurasi menganai service police dijelaskan pada konfigurasi VRF. 
d) Konfigurasi Switch CPE

[HP-GigabitEthernet1/0/9] combo enable fiber

Gambar 6. Mengaktifkan Penggunaan Fiber Optic

Langkah pertama dalam konfigurasi switch CPE adalah mengaktifkan penggunaan fiber aktif pada port yang terhubung ke perangkat penguji dengan menggunakan perintah "combo enable fiber" seperti yang tersaji pada Gambar 6.

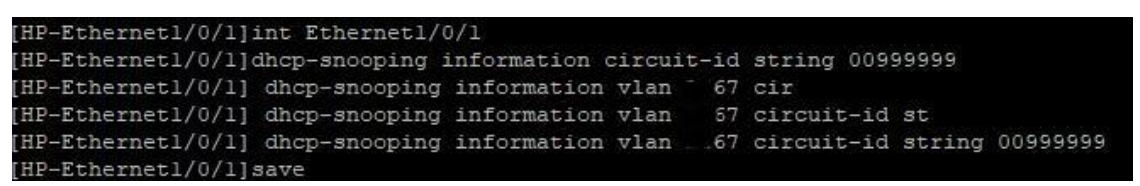

\section{Gambar 7. Memasukan circuit-id di CPE}

Langkah kedua dalam konfigurasi CPE adalah memasukan circuit-id dengan perintah "dhcpsnooping information circuit-id string 00999999" pada port yang digunakan untuk pengujian dan melakukan konfigurasi VLAN access sehingga VLAN yang sebelumnya dibuat di UPE dapat diakses di CPE seperti pada Gambar 7. Ketepatan dalam konfigurasi circuit-id sangat penting karena circuit-id digunakan untuk melakukan autorasi dan autentikasi pada RADIUS server. Apabila konfigurasi circuit-id salah maka service tidak bisa terbentuk karena RADIUS server melakukan reject access $\mathrm{CPE}$.

Urutan konfigurasi ini dilakukan dalam pembuatan service internet dengan menggunakan BNG. Apabila terdapat kebutuhan lebih dari satu IP, maka konfigurasi harus dilakukan sesuai dengan kebutuhan service. Setiap session hanya dapat menggunakan satu IP publik, sehingga untuk kebutuhan 4 IP publik pada satu service maka harus dilakukan empat kali konfigurasi. Hal tersebut menjadi salah satu kelemahan terbesar penggunaan BNG di ICON+ karena konfigurasi harus dilakukan berkali-kali serta karena konfigurasi BNG melibatkan dua pihak yaitu penyedia layanan (ISP / NSP) dan CPE maka proses konfigurasi memiliki resiko besar mengalami kesalahan karena masalah komunikasi antara kedua belah pihak serta membengkaknya waktu untuk konfigurasi.

\subsubsection{Konfigurasi VRF}

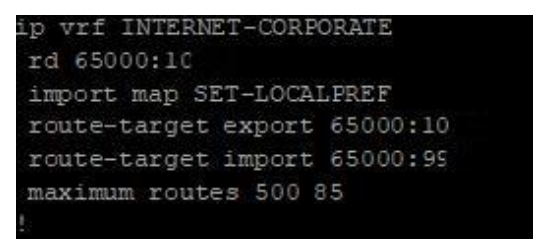

\section{Gambar 8. Konfigurasi VRF}

Konfigurasi pertama yang dilakukan pada VRF adalah membuat UPE terhubung ke VRF yaitu dengan membuat konfigurasi VRF INTERNET-CORPORATE pada UPE. Konfigurasi tersebut berisi tentang $\mathrm{rd}$ (route distiguisher), dan route target. Route distiguisher berfungsi untuk menemukan VRF INTERNET-CORPORATE pada cloud ICON+. Berikutnya merupakan konfigurasi route-target, konfigurasi ini terdiri dari export dan import. Export digunakan untuk mencari VRF INTERNET-CORPORATE dan import digunakan untuk mendapatkan informasi dari VRF INTERNET-CORPORATE berupa tabel routing. Pada konfigurasi route-target ini number yang digunakan export dan import berbeda karena komunikasi dalam jaringan yang menggunakan VRF INTERNET-CORPORATE bersifat hub and spoke. Komunikasi hanya dapat dilakukan VRF dengan perangkat-perangkat UPE namun dalam jaringan VRF tersebut antar perangkat UPE dalam penggunaan VRF INTERNET-CORPORATE tidak dapat saling berhubungan. 


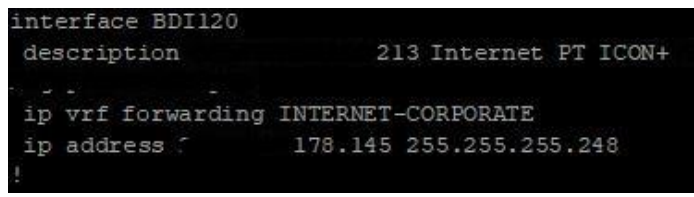

\section{Gambar 9. Pengalokasian IP VRF}

Langkah kedua adalah membuat interface, pengalokasian IP, dan mengkonfigurasi VRF pada interface tersebut untuk service seperti yang tersaji pada Gambar 9 Interface yang dibuat merupakan interface binding (BD) dengan nomor interface 120. penggunaan interface binding digunakan untuk meneruskan layanan dari router agar dapat meneruskan paket ke VLAN (switch).

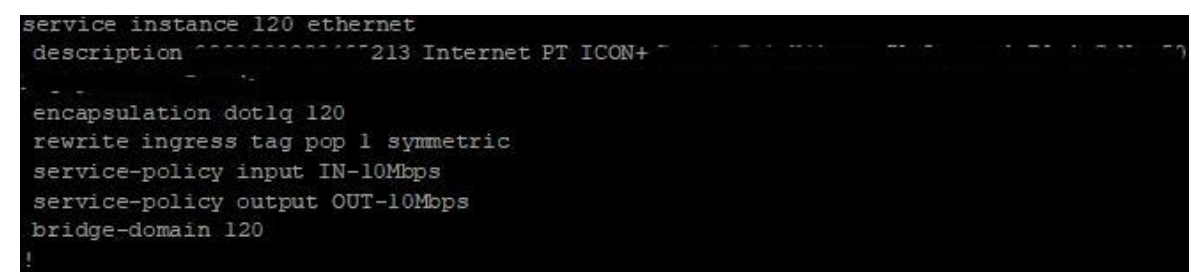

Gambar 10. Konfigurasi Service Policy

Berikutnya melakukan konfigurasi service yaitu membuat batasan kecepatan akses dari suatu service seperti pada Gambar 10. Batasan kecepatan yang dimaksud merupakan bandwidth maksimal yang dapat didapat oleh suatu service. Service-policy input digunakan untuk memberikan batasan pengguna dalam melakukan download data dan service-policy output digunakan untuk memberikan batasan pengguna dalam melalukan upload data dalam komunikasi dengan menggunakan service yang disediakan. Data input pada UPE artinya seluruh data yang di request dari CPE sedangkan data output pada UPE artinya seluruh data yang dikirimkan dari CPE.

\subsection{Penggunaan IP BNG dan VRF}

Analisis berikutnya tentang penggunaan sistem pengalokasian IP publik dengan BNG dan VRF. Pembagian IP publik dilakukan dengan asumsi network class A yang memiliki 8 bit network atau subnetwok awal 255.255.255.0 (/24) sehingga terdapat 256 host. Pada sistem pengalokasian IP publik dengan BNG pengelompokan subnetwok 255.255.255.0 (/24), sehingga jumlah IP network dan IP broadcast sama dengan jumlah per subnet awal. Pembagian subnet pada alokasi sangat mempengaruhi penggunaan IP. Sementara itu subnet awal yaitu 255.255.255.0 (/24) dengan 256 IP host di subneting kembali dengan VLSM sesuai kebutuhan pengalokasian IP sesuai skenario. Berikut contoh perhitungan subnet [9] :

a) Menghitung jumlah $\mathrm{H}$ (host) bit

Jika kebutuhan host valid sebanyak 1 host dan network class A dimulai dengan menggunakan 8 bit $\mathrm{N}$ (network)

Maka $2^{\mathrm{H}}-2 \geq 1$

Jadi $\mathrm{H}=2,2$ merupakan nilai paling mendekati nilai $\mathrm{H}$

b) Menghitung subnet yaitu $\mathrm{N}-\mathrm{H}$

$8-2=6 \mathrm{~N}$, sehingga terdapat 6 bit untuk membuat subnet

Jadi penggunaan bit : NNNNNNHH, penggunaaan subnet dipilih berdasarkan network yang paling besar sehingga penggunaan bit : 11111100 atau dalam classfull subnetting

11111111.11111111.11111111.11111100 atau

255.255.255.252 atau /30

c) Menghitung jumlah subnet yang terbentuk dari 8 bit $\mathrm{N}$

Jumlah host dari subnet awal 8 bit $\mathrm{N}=11111111=256$ host

Jumlah subnet $=$ Jumlah host dari subnet awal 8 bit $\mathrm{N}-2^{\mathrm{H}}$

Jumlah subnet $=256 / 4$

Jadi total subnet yang terbentuk adalah 64 subnet. 


\subsubsection{Penggunaan IP Publik dengan BNG}

Pengalokasian IP publik dengan BNG terpusat pada DHCP server. Salah satu kemampuan DHCP server dalam BNG adalah DHCP Relay, kemampuan tersebut membuat BNG mampu mengalokasikan IP kedalam subnetwork baru tanpa perlu melakukan pengalokasisan IP untuk network dan broadcast pada setiap membuat subnetting baru sehingga dapat menghemat penggunaan IP untuk network dan broadcast.
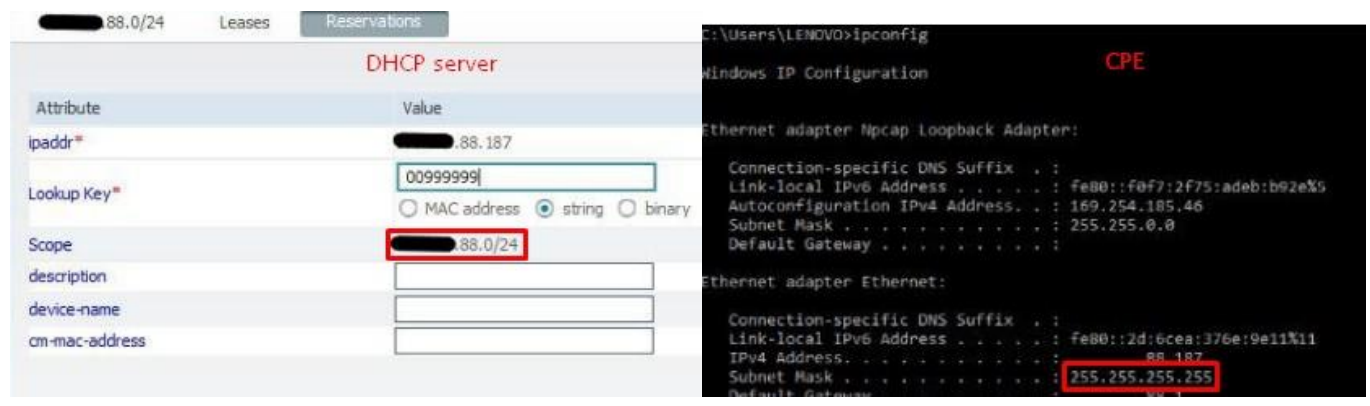

\section{Gambar 11. Perbedaan subnet DHCP server dan CPE pada BNG}

Gambar 11 membuktikan konfigurasi IP pada DHCP server subnetting /24 namun ketika di perangkat penguji atau CPE subnet menjadi /32 atau 255.255.255.255. Selain menjadi kelebihan BNG karena dengan penggunaan DHCP Relay tidak perlu mengalokasiakan IP network dan broadcast berkalikali jadi secara umum subnetting hanya dilakukan per /24, penggunaan DHCP Relay yang digunakan di ICON+ juga menjadi kelemahan karena subnetting dari subnet awal tidak dapat variatif hanya dapat melakukan subnetting ke 255.255.255.255 atau /32 saja. Hal tersebut yang mendasari sistem reservasi IP publik hanya dapat dilakukan per satu IP publik.

Tabel 3. Penggunaan IP publik dengan BNG

\begin{tabular}{cccccccc}
\hline No & Jumlah Service & $\begin{array}{c}\text { Kebutuhan } \\
\text { IP valid }\end{array}$ & $\begin{array}{c}\text { Jumlah } \\
\text { subnet /24 }\end{array}$ & $\begin{array}{c}\text { Jumlah subnet } \\
\text { layanan }\end{array}$ & $\begin{array}{c}\text { Jumlah IP } \\
\text { network }\end{array}$ & $\begin{array}{c}\text { Jumlah IP Jumlah IP } \\
\text { broadcast }\end{array}$ & layanan \\
\hline 1 & 800 service & 1 & 4 & 4 & 4 & 4 & 808 \\
2 & 1000 service & 1 & 4 & 4 & 4 & 4 & 1008 \\
3 & 1200 service & 1 & 5 & 5 & 5 & 5 & 1210 \\
4 & 800 service & 4 & 13 & 13 & 13 & 13 & 3226 \\
5 & 1000 service & 4 & 16 & 16 & 16 & 16 & 4032 \\
6 & 1200 service & 4 & 19 & 19 & 19 & 19 & 4838 \\
7 & 800 service & 8 & 26 & 26 & 26 & 26 & 6452 \\
8 & 1000 service & 8 & 32 & 32 & 32 & 32 & 8064 \\
9 & 1200 service & 8 & 38 & 38 & 38 & 38 & 9676 \\
\hline
\end{tabular}

Tabel 3 merupakan data yang menyimpulkan keseluruhan perhitungan IP publik dengan sistem pengalokasian BNG. Jumlah service dan kebutuhan IP valid sesuai dengan skenario penelitian. Kemampuan BNG dalam menjalankan DHCP Relay membuat jumlah subnet awal yaitu /24 sama dengan jumlah subnet untuk layanan serta jumlah IP network dan broadcast sama dengan jumlah pengalokasian subnet per /24. Nilai penggunaan subnet per /24 didapat dari Persamaan 1 dan 2 sebagai berikut

Alokasi maksimal dari subnet / 24 adalah 256 IP, $256-2=254$ ( pengurangan IP untuk 1 IP network dan 1 IP broadcast)

Jumlah subnet $/ 24=\mathrm{S}$

Jika Jumlah IP valid $\bmod 254=0$, maka $S=$ Jumlah IP valid / 254, selain itu

Jika Jumlah IP valid $\bmod 254 \neq 0$, maka $S=($ Jumlah IP valid div 254$)+1$ 
a) Service BNG dengan kebutuhan 1 IP publik

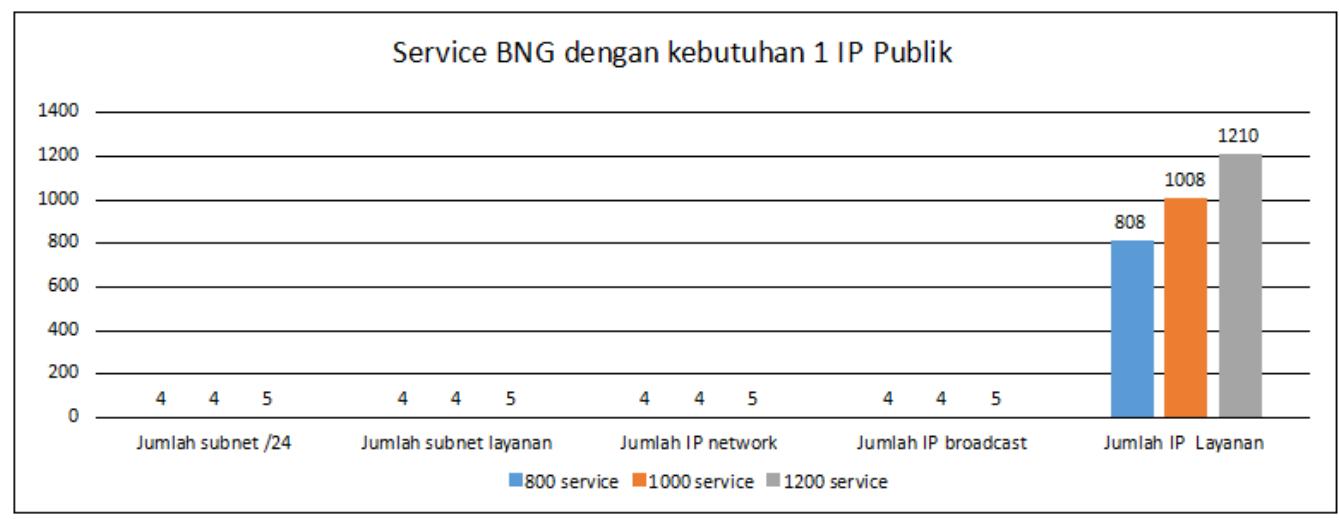

Gambar 12. Service BNG dengan kebutuhan 1 IP publik

Gambar 12 jumlah IP layanan yang tidak berbeda jauh dengan kebutuhan IP valid pada setiap service yaitu pada 800 service IP untuk layanan yang digunakan sebesar 808 IP, pada 1000 service IP untuk layanan yang digunakan sebesar 1008 IP, dan pada 1200 service IP untuk layanan yang digunakan sebesar 1210 IP.

b) Service BNG dengan kebutuhan 4 IP publik

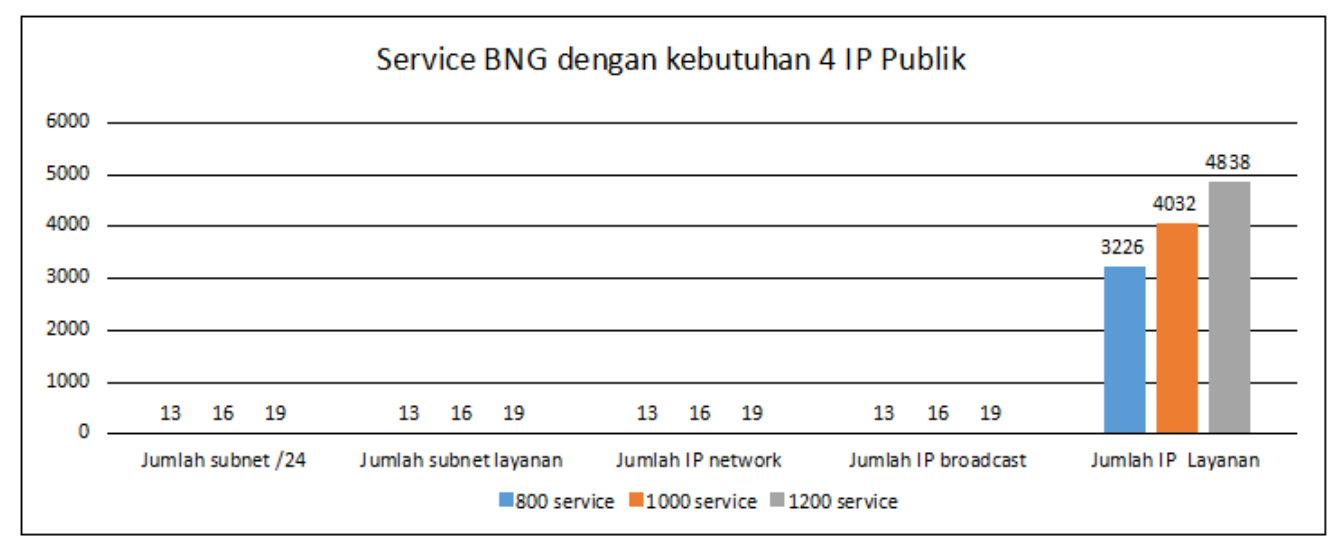

Gambar 13. Service BNG dengan kebutuhan 4 IP publik

Gambar 13 selisih jumlah IP layanan yang digunakan meningkat namun tidak terlalu signifikan dibandingkan dengan kebutuhan 1 IP pada setiap service.

c) Service BNG dengan kebutuhan 8 IP publik

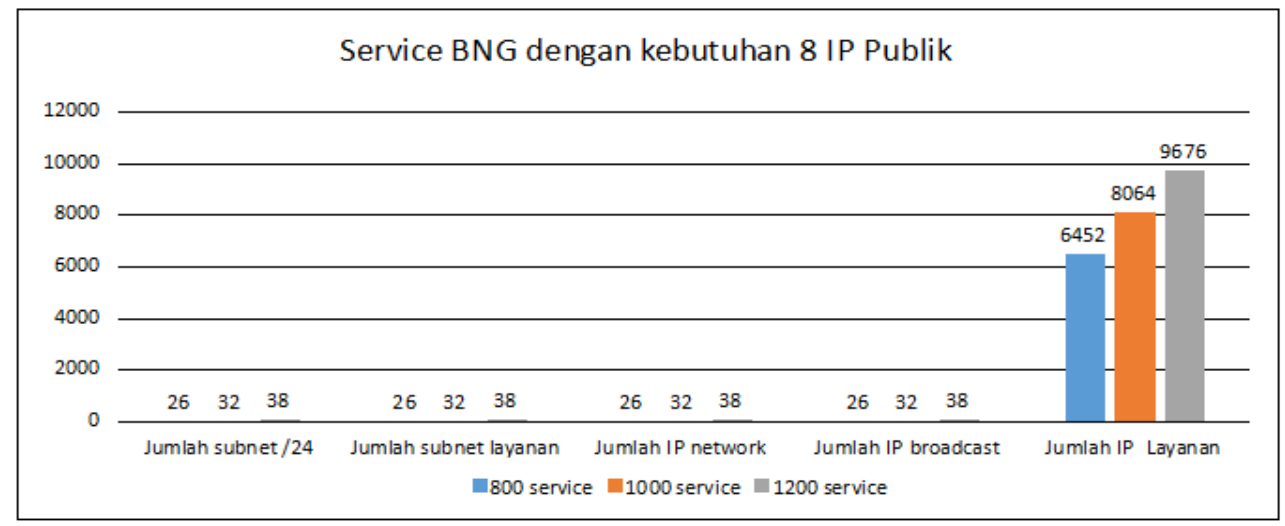

Gambar 14. Service BNG dengan kebutuhan 8 IP publik 
Gambar 14 jumlah IP layanan yang digunakan meningkat dikarenakan jumlah IP untuk network dan broadcast juga meningkat, namun peningkatan tersebut cukup normal dibandingkan dengan kebutuhan 4 IP pada setiap service.

\subsubsection{Penggunaan IP Publik dengan VRF}

Sistem pengalokasian IP publik dengan VRF yaitu dengan melakukan subbneting berdasarkan jumlah host yang dibutuhkan dari subnet awal (/24) dengan jumlah subnet baru disesuaikan dengan jumlah service yang dibutuhkan. IP pada alokasi subnet yang baru akan disebar ke UPE terdekat dari CPE untuk membuat service.

Tabel 4. Penggunaan IP publik dengan VRF

\begin{tabular}{cccccccc}
\hline No & Jumlah Service & $\begin{array}{c}\text { Kebutuha } \\
\text { nIP valid }\end{array}$ & $\begin{array}{c}\text { Jumlah } \\
\text { subnet /24 }\end{array}$ & $\begin{array}{c}\text { Jumlah } \\
\text { subnet } \\
\text { layanan }\end{array}$ & $\begin{array}{c}\text { Jumlah IP } \\
\text { network }\end{array}$ & $\begin{array}{c}\text { Jumlah } \\
\text { IP } \\
\text { broadcast }\end{array}$ & $\begin{array}{c}\text { Jumlah IP } \\
\text { layanan }\end{array}$ \\
\hline 1 & 800 service & 1 & 13 & 800 & 800 & 800 & 3200 \\
2 & 1000 service & 1 & 16 & 1000 & 1000 & 1000 & 4000 \\
3 & 1200 service & 1 & 19 & 1200 & 1200 & 1200 & 4800 \\
4 & 800 service & 4 & 25 & 800 & 800 & 800 & 6400 \\
5 & 1000 service & 4 & 32 & 1000 & 1000 & 1000 & 8000 \\
6 & 1200 service & 4 & 38 & 1200 & 1200 & 1200 & 9600 \\
7 & 800 service & 8 & 50 & 800 & 800 & 800 & 12800 \\
8 & 1000 service & 8 & 63 & 1000 & 1000 & 1000 & 16000 \\
9 & 1200 service & 8 & 75 & 1200 & 1200 & 1200 & 19200 \\
\hline
\end{tabular}

Tabel 4 menunjukan hasil perhitungan jumlah subbneting baru (pembagian dari subnet /24) sama dengan jumlah service menyebabkan jumlah IP yang digunakan untuk network dan broadcast juga sama dengan jumlah service. Sementara jumlah IP layanan didapat dari jumlah IP host dalam subnet dikalikan dengan jumlah service. Perumusan lebih lengkap pada perumusan 3 hingga 9 sebagai berikut

Jumlah service $=$ Jumlah subnet layanan $=$ Jumlah IP network $=$ Jumlah IP broadcast

Jumlah IP layanan $=$ Jumlah IP host dalam subnet $\times$ Jumlah service

Jumlah IP host dalam subnet $/ 24=256$,

Jumlah IP host dalam subnetting baru $=\mathrm{P}$, Jumlah service $=Q$

Jumlah subnet $/ 24=\mathrm{S}$, Jumlah subnetting baru dalam subnetting lama $=\mathrm{R}$

$\mathrm{R}=256 / \mathrm{P}$

Jika $\mathrm{Q} \bmod \mathrm{R}=0$, maka $\mathrm{S}=\mathrm{Q}$ div $\mathrm{R}$, selain itu

Jika $\mathrm{Q} \bmod \mathrm{R} \neq 0$, maka $\mathrm{S}=\mathrm{Q} \operatorname{div} \mathrm{R}+1$.

a) Service VRF dengan kebutuhan 1 IP publik

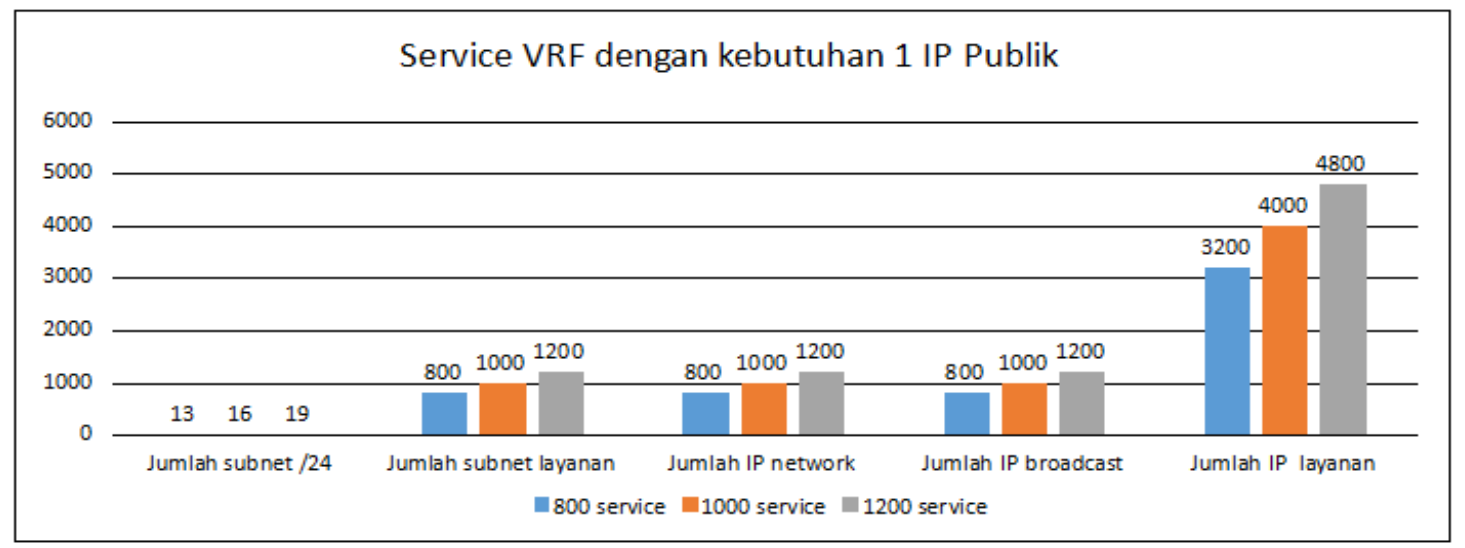

Gambar 15. Service VRF dengan kebutuhan 1 IP publik

Data pada Gambar 15 menunjukan bahwa jumlah IP layanan berbeda jauh dengan kebutuhan IP valid pada setiap service yaitu pada 800 service IP untuk layanan yang digunakan sebesar 3200 IP, 
pada 1000 service IP untuk layanan yang digunakan sebesar 4000 IP, dan pada 1200 service IP untuk layanan yang digunakan sebesar 4800 IP. Jumlah IP layanan yang digunakan secara setiap service menunjukan nilai yang tiga kali lebih besar dari kebutuhan IP valid pada setiap service.

b) Service VRF dengan kebutuhan 4 IP publik

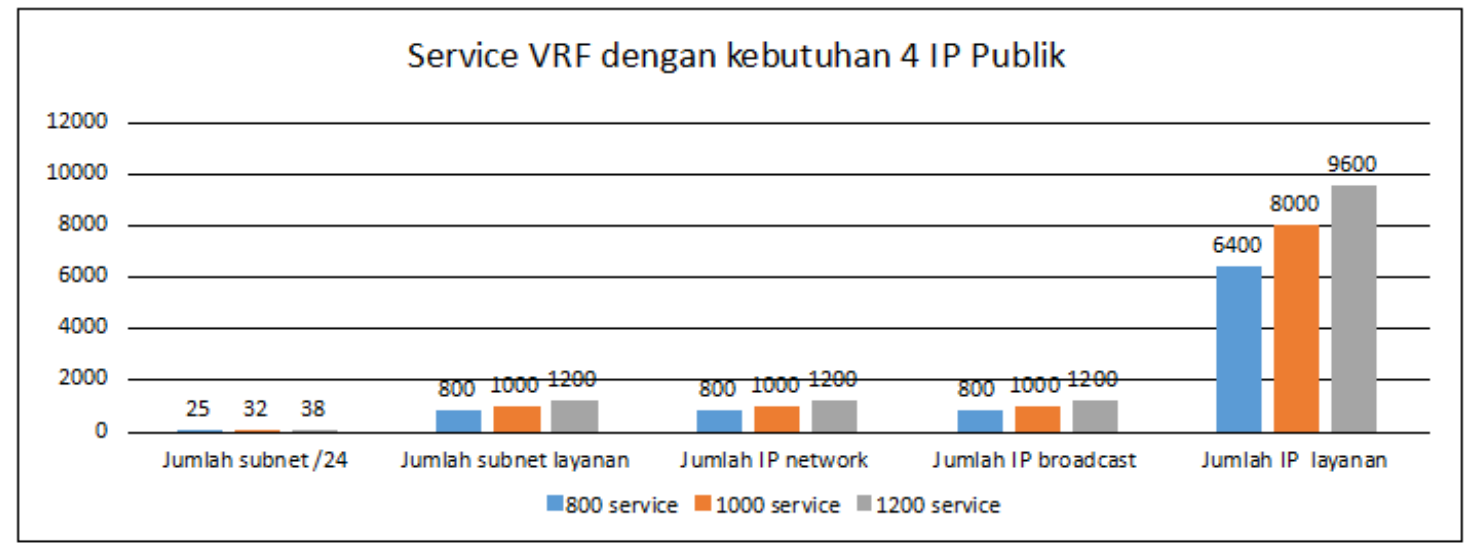

Gambar 16. Service VRF dengan kebutuhan 4 IP publik

Data pada Gambar 16 menunjukan bahwa jumlah IP layanan masih berbeda jauh dengan kebutuhan IP valid pada setiap service yaitu pada 800 service IP untuk layanan yang digunakan sebesar 6400 IP, pada 1000 service IP untuk layanan yang digunakan sebesar 8000 IP, dan pada 1200 service IP untuk layanan yang digunakan sebesar 9600 IP. Jumlah IP layanan yang digunakan secara setiap service menunjukan nilai yang satu kali lebih besar dari kebutuhan IP valid pada setiap service.

c) Service VRF dengan kebutuhan 8 IP publik

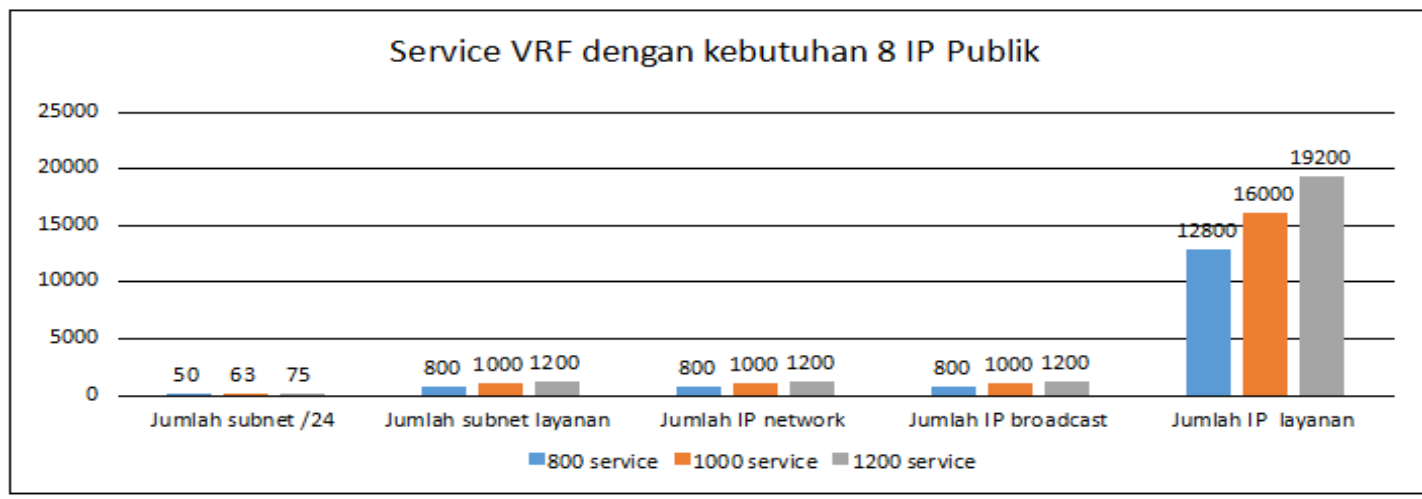

Gambar 17. Service VRF dengan kebutuhan 8 IP publik

Gambar 17 menunjukan bahwa jumlah IP layanan masih berbeda jauh dengan kebutuhan IP valid pada setiap service yaitu pada 800 service IP untuk layanan yang digunakan sebesar 12800 IP, pada 1000 service IP untuk layanan yang digunakan sebesar 16000 IP, dan pada 1200 service IP untuk layanan yang digunakan sebesar 19200 IP. Jumlah IP layanan yang digunakan secara setiap service menunjukan nilai yang satu kali lebih besar dari kebutuhan IP valid pada setiap service. 


\subsubsection{Perbandingan pengunaan IP publik BNG dan VRF}

Berdasarkan analisis data sebelumnya membahas tentang penggunaan IP Publik dengan menggunakan sistem pengalokasian BNG dan VRF secara terpisah. Pada penjelasan subbab ini membandingkan penggunaan IP publik yang terrangkum dalam Tabel 5. Data dalam tabel tersebut menunjukan bahwa penggunaan IP publik dengan sistem pengalokasian BNG dan VRF terdapat perbandingan yang sangat jauh.

Tabel 5. Perbandingan penggunaan IP publik BNG dengan VRF

\begin{tabular}{|c|c|c|c|c|c|c|c|c|c|c|c|c|}
\hline \multirow[t]{2}{*}{ No } & \multirow[t]{2}{*}{ Jumlah service } & \multirow[t]{2}{*}{$\begin{array}{c}\text { Kebutuh } \\
\text { an IP } \\
\text { valid }\end{array}$} & \multicolumn{2}{|c|}{$\begin{array}{c}\text { Jumlah } \\
\text { subnet } / 24\end{array}$} & \multicolumn{2}{|c|}{$\begin{array}{c}\text { Jumlah } \\
\text { subnet } \\
\text { layanan }\end{array}$} & \multicolumn{2}{|c|}{$\begin{array}{c}\text { Jumlah IP } \\
\text { network }\end{array}$} & \multicolumn{2}{|c|}{$\begin{array}{c}\text { Jumlah } \\
\text { IP } \\
\text { broadcast }\end{array}$} & \multicolumn{2}{|c|}{$\begin{array}{c}\text { Jumlah IP } \\
\text { layanan }\end{array}$} \\
\hline & & & $\begin{array}{c}B N \\
G\end{array}$ & $V R F$ & $B N G$ & $V R F$ & $B N G$ & $V R F$ & $\begin{array}{c}B N \\
G\end{array}$ & $V R F$ & $B N G$ & $V R F$ \\
\hline 1 & 800 service & 1 & 4 & 13 & 4 & 800 & 4 & 800 & 4 & 800 & 808 & 3200 \\
\hline 2 & 1000 service & 1 & 4 & 16 & 4 & 1000 & 4 & 1000 & 4 & 1000 & 1008 & 4000 \\
\hline 3 & 1200 service & 1 & 5 & 19 & 5 & 1200 & 5 & 1200 & 5 & 1200 & 1210 & 4800 \\
\hline 4 & 800 service & 4 & 13 & 25 & 13 & 800 & 13 & 800 & 13 & 800 & 3226 & 6400 \\
\hline 5 & 1000 service & 4 & 16 & 32 & 16 & 1000 & 16 & 1000 & 16 & 1000 & 4032 & 8000 \\
\hline 6 & 1200 service & 4 & 19 & 38 & 19 & 1200 & 19 & 1200 & 19 & 1200 & 4838 & 9600 \\
\hline 7 & 800 service & 8 & 26 & 50 & 26 & 800 & 26 & 800 & 26 & 800 & 6452 & 12800 \\
\hline 8 & 1000 service & 8 & 32 & 63 & 32 & 1000 & 32 & 1000 & 32 & 1000 & 8064 & 16000 \\
\hline 9 & 1200 service & 8 & 38 & 75 & 38 & 1200 & 38 & 1200 & 38 & 1200 & 9676 & 19200 \\
\hline
\end{tabular}

Proses pengalokasian IP mempengaruhi penggunaan IP layanan. Sistem pengalokasian IP publik dengan BNG tidak menunjukan perbedaan yang jauh dalam penggunaan IP layanan dalam memenuhi kebutuhan ketiga skenario service serta kebutuhan IP valid (IP publik untuk CPE) pada setiap service. Penggunaan pengalokasian IP publik dengan VRF memiliki tren sendiri. Apabila kebutuhan IP valid semakin mendekati jumlah maksimal IP valid dari subnetting maka perbedaan penggunaan IP layanan dan IP valid sesungguhnya akan lebih sedikit. Hal tersebut dibuktikan dengan data perhitungan IP pada seluruh service dengan kebutuhan IP valid sebanyak 4 IP dan 8 IP.

Pada kebutuhan 4 IP valid dilakukan subnetting 255.255.255.248 (/29) terdapat 8 IP host dalam subnet. IP valid dalam subnetting tersebut hanya digunakan 4 IP atau $\frac{1}{2}$ dari jumlah IP host dalam subnet. Sama halnya dengan skenario kebutuhan 8 IP valid dilakukan subnetting 255.255.255.240 (/28) terdapat 16 IP host dalam subnet. IP valid dalam subnetting tersebut hanya digunakan 8 IP atau $\frac{1}{2}$ dari jumlah IP valid yang ada. Sehingga penggunaan IP layanan satu kali lebih banyak dari kebutuhan IP valid sesungguhnya.

Penggunaan IP dengan VRF semakin tidak maksimal karena pengalokasian IP network, broadcast dilakukan pada setiap service menyebabkan membengkaknya penggunaan IP layanan. Hal ini terbukti pada skenario dengan kebutuhan 1 IP publik dalam memenuhi kebutuhan seluruh service. Pada skenario tersebut pemenuhan kebutuhan IP dilakukan dengan melakukan subnetting 255.255.255.252 (/30) dengan 4 IP host. IP tersebut digunakan untuk 1 IP sebagai network, 1 IP sebagai broadcast, dan 1 IP untuk memenihi kebutuhan IP publik untuk CPE, sehingga dalam memenuhi kebutuhan 1 IP valid dibutuhkan setidaknya 3 IP publik dengan sistem pengalokasisan VRF. Sementara dengan sistem pengalokasian BNG dilakukan pengelompokan IP per subnet /24 dengan jumlah IP host 256 IP. Pengalokasian IP untuk network dan broadcast dilakukan per subnet /24 juga sehingga tidak boros dalam penggunaan IP sehingga terdapat 254 IP valid yang dapat digunakan untuk membuat service dengan berbagai kebutuhan IP valid. 


\subsection{Performa Service Internet dengan Broadband Network Gateway}

\subsubsection{Pengecekan session service}

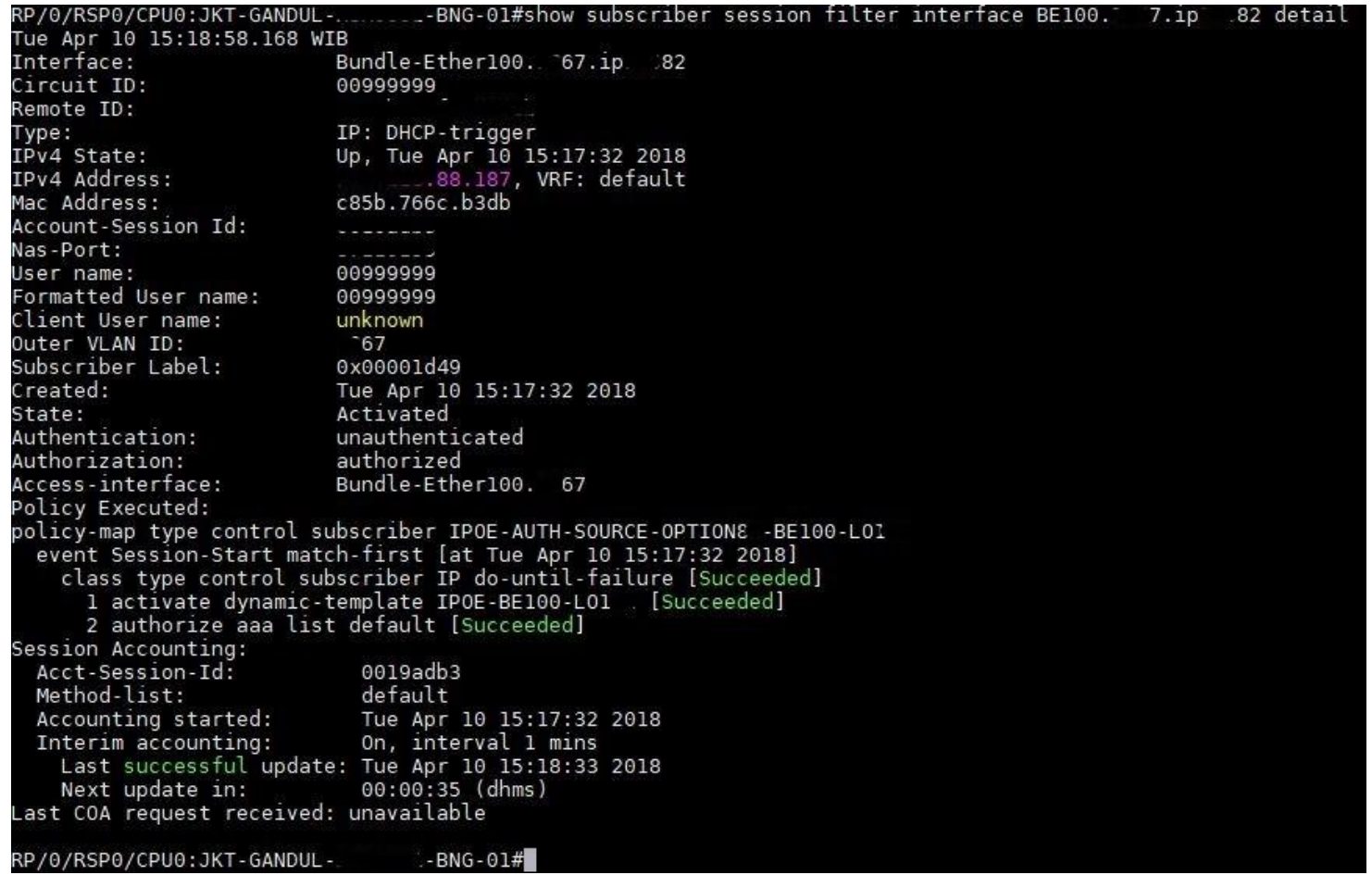

\section{Gambar 18. Pengecekan session di router BNG}

Pengecekan session suatu service telah aktif, dilakukan di router BNG. Pada Gambar 18 ditampilkan hasil pengecekan session, dari gambar tersebut konfigurasi yang telah dibuat sebelumnya yaitu dengan circuit-id 0099999 dengan IP address XXX.XX.88.187. MAC address merupakan alamat milik perangkat penguji. (ERI-PC) Tanda dari session aktif ketika policy map sukses seperti yang tertampil pada Gambar 19 berwarna hijau. Gambar tersebut juga menunjukan bahwa session menggunakan jenis IPoE (IP over Ethernet). Selain itu pada gambar tersebut ditunjukan pula MAC address dari perangkat penguji serta tanggal pembuatan dan tanggal awal pencacatan proses accounting dari suatu service.

Setelah pengecekan session selesai dan session aktif proses perekaman data performa dilakukan oleh WireShark dan dengan menggunakan speed test ICON+. Pengambilan data dilakukan dengan mengakses website yang menggunakan server dalam negeri seperti detik.com maupun dengan website yang menggunakan server luar negeri seperti facebook.com . 


\subsubsection{Analisis Throughput}

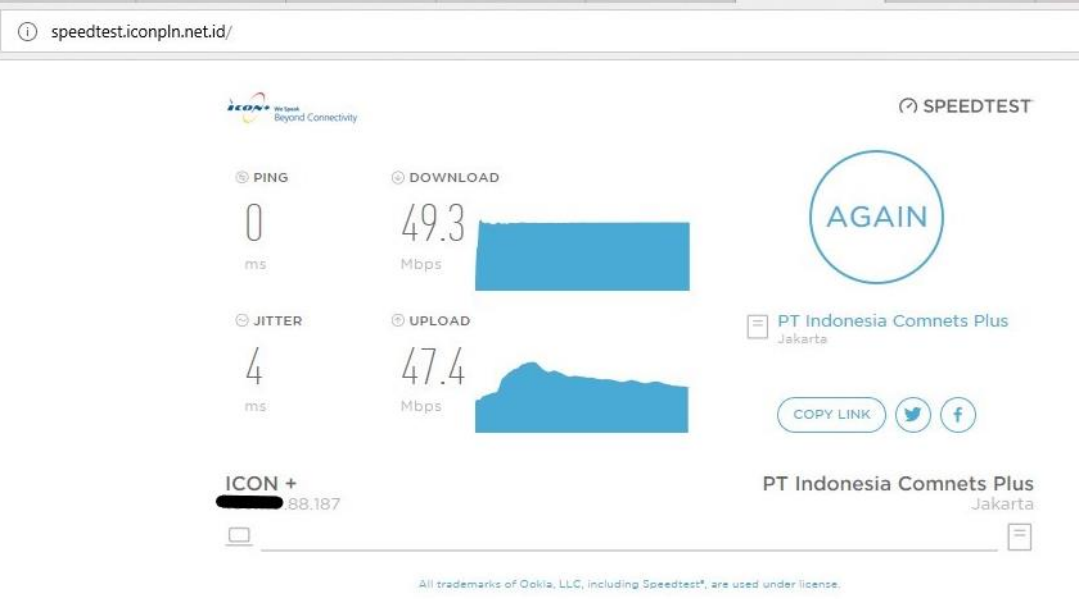

Gambar 19. Hasil Pengujian Dengan Speed Test

Pengujian throughput dilakukan dengan melakukan speed test dengan speed test ICON+ seperti yang tersaji pada Gambar 19. Pada gambar tersebut didapat nilai dari ping, jitter, download dan upload. Nilai download dan upload merupakan nilai throughput. Kecepatan rata-rata throughput adalah 48.35 Mbps atau setara $96.7 \%$ dari alokasi bandwidth yaitu 50Mbps artinya service internet dengan menggunakan BNG dapat dinilai sangat bagus [10]. Dari data ini juga dapat dikatakan meskipun untuk mengakses internet CPE harus melalui BNG terlebih dahulu nilai throughput tidak terlalu dipengaruhi oleh hal tersebut.

\subsubsection{Analisis Jitter}

Pengujian jitter dilakukan dengan melakukan speed test dengan speed test ICON+ seperti yang tersaji pada Gambar 20. Nilai jitter yang didapat dari pengujian yaitu $4 \mathrm{~ms}$ sehingga menurut standar degradasi [10] dapat dikatakan bagus.

\subsubsection{Analisis Delay}

Pengujian delay dilakukan dengan melakukan perekaman data performa dengan menggunakan WireShark. Perhitungan delay hanya dilakukan pada protokol TCP dan UDP karena protokol tersebut paling banyak digunakan untuk akses internet dalam pengujian service internet dengan menggunakan BNG ini. Waktu FIN dan reset diabaikan. FIN merupakan waktu jeda ketika suatu aliran TCP selesai dilakukan hingga terdapat adanya aliran TCP kembali. 
bng ambil data 410 2018.pcapng

File Edit View Go Capture Analyze Statistics Telephony Wireless Tools Help

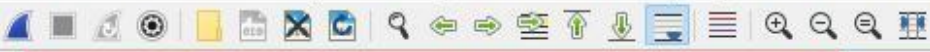

(tcp.port $==80 \|$ udp.port $==80$ ) and tcp. flags. fin $==0$ and tcp. flags.reset $==0$ |

Time Source

280.000000

290.003348

300.000115

310.000214

320.003692

330.001495

340.000002

350.000061

360.001459

370.000004

380.000085

518.794312

530.003058

81 26.251...

830.194276

840.000197

850.005247

860.193988

Destination

Protocol

Length TCP delta Delta time displayed Info

8.187

6.18

$\begin{array}{ll}.181 & \text { TCP } \\ .187 & \text { TCP }\end{array}$

$66 \quad 0.001090$

509

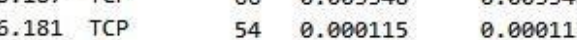

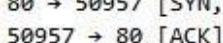

8.187

8.187

6.181 HTTP

2670.000214

0.000214

GET /en-US/livet:

$\begin{array}{llll}8.187 & \text { TCP } & 60 & 0.003692\end{array}$

0.003692

$80 \rightarrow 50957$ [ACK]

8.187 TCP $\quad 1514 \quad 0.001495$

0.001495

$80 \rightarrow 50957$ [ACK]

6.181

$8.187 \mathrm{TCP}$

15140.000002

0.000002

$80 \rightarrow 50957[\mathrm{ACK}]$

$\begin{array}{lllll}5.181 & \text { TCP } & 54 & 0.000061 & 0.000061\end{array}$

$50957 \rightarrow 80$ [ACK]

8.187

$8.187 \mathrm{TCP}$

15140.001459

0.001459

$80 \rightarrow 50957[\mathrm{ACK}]$

$8.187 \mathrm{HTTP} / \mathrm{XML} 2620.000004 \quad 0.000004 \quad$ HTTP/1.1 200 OK

6.181

8.187

$6.181 \mathrm{TCP}$

0.000085

$50957 \rightarrow 80[$ ACK $]$

$\begin{array}{lllll}7.4 & \text { TCP } & 54 & 0.000082 & 8.794312\end{array}$

$50955 \rightarrow 80$ [ACK]

$0.003058 \quad 80 \rightarrow 50955$ [ACK]

7.4

8.187 TCP

$60 \quad 0.003015$

$50958 \rightarrow 80$ [SYN]

$\begin{array}{lll}66 & 0.396647 & 26.251270\end{array}$

16

181

$66 \quad 0.071251$

0.194276

$\begin{array}{llll}54 & 0.000197 & 0.000197 & 50958 \rightarrow 80 \text { [ACK] } \\ 251 & 0.005247 & 0.005247 & \text { GET /wpsv6intern }\end{array}$

$80 \rightarrow 50958$ [ACK $]$

\section{Gambar 20. Filtering Mencari Delay}

Setelah proses filtering pada Gambar 20 selesai dilakukan berikutnya adalah menampilkan kolom TCP delta pada tampilan WireShark. TCP delta merupakan selisih waktu kedatangan paket dari waktu pengiriman paket. Nilai dari delay yaitu $22.058 \mathrm{~ms}$ sehingga delay dari performa service internet dengan BNG dapat dikatakan sangat baik karena menurut standar degradasi [10], nilai delay yang sangat baik dalam performa jaringan adalah yang kurang dari 150ms.

\subsubsection{Analisis Packet Loss}

Nilai packet loss didapat dengan melakukan filtering data di WireShark dengan menuliskan perintah “tcp.analysis.lost_segment”. Nilai packet loss pengujian service internet dengan menggunakan BNG ini dapat dikatakan baik karena bernilai $0.1 \%$ [10].

\section{KESIMPULAN}

Kebutuhan IP publik yang sedikit sangat cocok dikonfigurasi dengan BNG, sedangkan konfigurasi VRF lebih cocok digunakan untuk kebutuhan service internet dengan kebutuhan banyak IP Publik karena sistem konfigurasi BNG per satu IP dan memiliki tahapan konfigurasi lebih panjang yang menimbulkan resiko troubleshooting dan proses konfigurasi yang lebih lama dibandingkan dengan konfigurasi pada VRF yang hanya membutuhkan satu tahap konfigurasi di PE paling dekat dengan CPE.

Sistem pengalokasian IP publik dengan BNG mengalokasikan IP network dan broadcast pada subnet 255.255.255.0 (/24) kemudian membagikan IP untuk CPE dengan subnetting 255.255.255.255 (/32), sedangkan pada VRF mengalokasikan IP network dan broadcast dilakukan pada setiap service serta subnetting disesuaikan dengan kebutuhan service.

Performa service internet dengan menggunakan BNG sangat baik pada parameter throughput dengan nilai $96.7 \%$ dan delay dengan nilai $22.058 \mathrm{~ms}$ serta baik untuk parameter packet loss dengan nilai $0.1 \%$ dan jitter dengan nilai $4 \mathrm{~ms}$.

\section{UCAPAN TERIMA KASIH}

Terima kasih kepada PT. Indonesia Comnet Plus khususnya kepada Bapak Puji Sariyono selaku Manager Divisi Configuration Management yang telah membantu perizinan pengambilan data dan Bapak Fraedi Hangga H selaku pembimbing dan Supervisor Divisi Configuration Management selama magang, serta seluruh pihak yang telah membantu pengerjaan penelitian ini.

\section{DAFTAR PUSTAKA}

[1] ICON+, “About - ICON+," 2017. [Online]. Available: http://www.iconpln.co.id/en/about/. 
[Accessed: 08-Jun-2018].

[2] S. Jose, "Cisco ASR 9000 Series Aggregation Services Router Broadband Network Gateway Configuration Guide, Release 6 . 0 . x," no. 6387, 2016.

[3] S. Malik, ( MPLS ) PADA TEKNOLOGI VIRTUAL PRIVATE NETWORK. 2015.

[4] B. H. Chandana, P. Darsini, and M. Devi, "Inter-Provider VPN Network using Back-To-Back VRF and MP-eBGP Method," no. August, pp. 358-363, 2017.

[5] M. P. Clark, Protocols, Design and Operation. 2003.

[6] Cisco, "Broadband Network Gateway Overview," pp. 1-10.

[7] Z. Zhen and S. Sampalli, "Saving Public Addresses in Mobile IP," 2006.

[8] S. Ramadhan, M. Fathurahman, T. Elektro, B. Multimedia, and P. N. Jakarta, "Analisis Performandsi Jaringan Router Fortigate 50E Pada Area Wilayah Gorontalo, Kendari, dan Mamuju," pp. 1-9, 2014.

[9] Scott Empson, CCNA Portable Command Guide (CCNA Self-Study) - Scott Empson - Google Books, 2nd ed. USA: Cisco Press, 2008.

[10] Telecommunications and Internet Protocol Harmonization Over Networks (TIPHON), “Tr 101 329," ETSI, vol. 1, no. General aspects of Quality of Service (QoS), pp. 1-37, 1999. 